\title{
Harmonia com a natureza: um paradigma biocêntrico para o direito ${ }^{1}$
}

https://doi.org/10.21830/9789585284845.06

\author{
Mariana Ribeiro Santiago ${ }^{2}$ \\ Escuela Militar de Cadetes "General José María Córdova”
}

\section{Introduçáo}

Desde que o direito ao desenvolvimento foi reconhecido na seara internacional como um direito humano inalienável, com ênfase para a Declaração sobre Direito ao Desenvolvimento (Resolução no 41/128, da Assembléia Geral das Naçôes Unidas, 1986), intensificaram-se os estudos sobre a matéria, em diversas perspectivas, preponderando, na seara internacional, a visão do desenvolvimento sustentável (Relatório Brundtland, Rio 92, Declaração de Joanesburgo sobre Desenvolvimento Sustentável, Rio+20 e Cúpula de Desenvolvimento Sustentável).

A proposta do presente trabalho é demonstrar, todavia, a insuficiência do discurso mainstream, da doutrina do desenvolvimento sustentável - focada, pela perspectiva antropocêntrica, na qualidade de vida da atual sociedade e geraçóes futuras- , para a efetiva proteção do meio ambiente.

O estudo justifica-se pela percepção da gravidade das questóes ambientais que atingem a sociedade global na atualidade, o que implica na busca de

1 Este capítulo hace parte de los resultados del proyecto de investigación "La legitimidad de las Fuerzas Militares en la geopolítica nacional e internacional de Colombia” del Grupo de Investigación en Ciencias Militares, de la Escuela Militar de Cadetes "General José María Córdova” (ESMIC), registrado con el código COL0082556 de Minciencias. Los puntos de vista y los resultados de este artículo pertenecen a la autora y no reflejan necesariamente los de la ESMIC.

2 Pós-doutora em Direito pela Justus-Liebig-Universität Gießen (Alemanha). Doutora e mestre em Direito pela Pontifícia Universidade Católica de São Paulo - PUCSP. Professora do Programa de Pós-Graduação Stricto Sensu da Universidade de Marília - UNIMAR. Editora-chefe da Revista Argumentum. Membro do Projeto Harmony with Nature, de iniciativa das Naçóes Unidas. Advogada. Orcid: https://orcid.org/0000-0001-7226-1021 - Contacto: ppgd@unimar.br 
soluçôes eficazes, partindo da percepção da necessidade de se conferir maior protagonismo à natureza em matéria de proteçáo ambiental.

Objetiva-se com o presente estudo confrontar as doutrinas do desenvolvimento sustentável e teorias de pós-desenvolvimento, expondo as criticas sofridas pelo discurso hegemônico, que apontam para uma adjetivação acerca do desenvolvimento que maquia a emergência de adoção de medidas mais concretas sobre o meio ambiente, verificando-se se é viável juridicamente à aplicação do paradigma biocêntrico ao tema.

Para tanto, abordar-se-á no primeiro tópico a teoria do desenvolvimento sustentável e a critica do pós-desenvolvimento. Após isso, é realizada uma exposição sobre a doutrina relacionada aos direitos da Natureza, de perspectiva biocêntrica, e sua inserção na seara internacional e nacional.

Por fim, para a concretização da pesquisa observa revisão bibliográfica, com amparo na doutrina estrangeira e nacional, bem como análise de documentos. $\mathrm{Na}$ abordagem, utiliza-se os método dialético, partindo-se da análise de diferentes e conflitantes vertentes sobre o tema do desenvolvimento e o meio ambiente, em contraponto, para o aprofundamento da sua compreensão, bem como das rivais perspectivas antropocêntrica e biocêntrica.

\section{Do desenvolvimento sustentável ao pós-desenvolvimento: uma análise dialética}

É cediço que a criação da Organização das Naçôes Unidas (ONU), em 1945, resulta de um esforço histórico e um consenso internacional, posteriores aos horrores da Segunda Grande Guerra, sobre a necessidade de promover a estabilidade e o bem-estar indispensáveis às relações pacíficas e amistosas entre as Naçôes, inclusive pela via do desenvolvimento econômico.

A partir de então, o direito ao desenvolvimento foi objeto de inúmeros instrumentos internacionais dos quais o Brasil é signatário, com ênfase para a Declaração sobre Direito ao Desenvolvimento (Resolução no 41/128, da Assembléia Geral das Naçóes Unidas, 1986), que, em seu art. 1º, reconhece o desenvolvimento como um direito humano inalienável, em virtude do qual toda pessoa e todos os povos estão habilitados a participar do desenvolvimento 
econômico, social, cultural e político, a ele contribuir e dele desfrutar, no qual todos os direitos humanos e liberdades fundamentais possam ser plenamente realizados (United Nations, 2019b).

Posteriormente, em 1993, a Declaração de Viena, resultado da Conferência de Direitos Humanos, traz cinquenta e sete citaçóes para a palavra desenvolvimento, incluindo a necessidade de promoção e o encorajamento do respeito pelos Direitos Humanos e pelas liberdades fundamentais para todos, bem como do respeito pelo princípio da igualdade de direitos e da autodeterminação dos povos, da paz, da democracia, da justiça, da igualdade, do Estado de Direito, do pluralismo, do desenvolvimento, de melhores padróes de vida e da solidariedade (United Nations, 2019g).

Sob tal perspectiva, o desenvolvimento deve ser entendido como um processo global voltado à melhoria da qualidade de vida dos indivíduos, de forma ativa, livre e significativa, cabendo ao Estado o dever de criar as condiçōes favoráveis ao desenvolvimento supranacional e interno (Silveira \& Naspolini, 2013).

Paralelamente ao estudo e regulamentação do desenvolvimento como um direito humano, a questão ambiental foi objeto das atividades das Naçôes Unidas, já em 1972, resultando na Conferência das Naçôes Unidas sobre o Meio Ambiente Humano, em Estocolmo, que originou uma declaração reconhecendo a necessidade de um critério e de princípios comuns que ofereçam aos povos do mundo inspiração e guia para preservar e melhorar o meio ambiente humano. Dessa conferência também foi originado o Programa das Naçôes Unidas para o Meio Ambiente (ONU Meio Ambiente), passando a coordenar os trabalhos acerca do meio ambiente global (Naçôes Unidas Brasil, 2019a).

A Conferência das Nações Unidas sobre o Ambiente Humano, de 1972, de fato, colocou a questão do meio ambiente na agenda internacional, tendo sendo precedida pelo encontro Founex, de 1791, e de uma série de encontros e relatórios internacionais sobre o tema. Durante a preparação da Conferência de Estocolmo, duas posiçóes se opunham: a que previa abundância (the cornucopians), considerando descabidas as preocupaçóes com o meio ambiente, e os catastrofistas (doomsayers), com suas previsóes sobre o apocalipse iminente decorrente do contínuo crescimento demográfico e econômico. $\mathrm{Na}$ Conferência de Estocolmo, ambas as posições extremas foram descartadas (Sachs, 2009). 
Os temas do desenvolvimento e do meio ambiente ganham convergência em 1987, com o Relatório Brundtland (United Nations, 2019f), também conhecido como "Nosso futuro comum", onde há menção ao desenvolvimento sustentável, como aquele que atende às necessidades do presente sem comprometer a possibilidade de as geraçôes futuras atenderem às suas necessidades.

A partir desse marco, foi realizada a Conferência das Naçóes Unidas sobre o Meio Ambiente e o Desenvolvimento, também lembrada como a "Cúpula da Terra”, em 1992, no Rio de Janeiro, com a adoção da Agenda 21 (United Nations, 2019a), um documento assinado por 179 (cento e setenta e nove países, determinando, como áreas de ação: "proteger a atmosfera; combater o desmatamento, a perda de solo e a desertificação; prevenir a poluição da água e do ar; deter a destruição das populaçóes de peixes e promover uma gestão segura dos resíduos tóxicos", alem de abordar questóes como pobreza e a dívida externa dos países em desenvolvimento; padróes insustentáveis de produção e consumo; pressóes demográficas e a estrutura da economia internacional.

O ideal do desenvolvimento sustentável repercutiu, ainda, de forma implícita na Convenção Quadro das Naçôes Unidas sobre Mudanças Climáticas (1992), no Protocolo de Kyoto (1997), na Segunda Conferência da ONU sobre Assentamentos Humanos (Istambul, 1999), na Sessão Especial da Assembleia Geral sobre Pequenos Estados Insulares em Desenvolvimento (Nova York, 1999); na Cúpula do Milênio (Nova York, 2000) e na Reunião Mundial de 2005 (Nações Unidas Brasil, 2019a).

Contudo, é na Declaração de Joanesburgo sobre Desenvolvimento Sustentável (2002) que se apresenta o tripé da sustentabilidade, quando os Estados-Membros concordaram em assumir "a responsabilidade coletiva de fazer avançar e fortalecer os pilares interdependentes e mutuamente apoiados do desenvolvimento sustentável - desenvolvimento econômico, desenvolvimento social e proteção ambiental - nos âmbitos local, nacional, regional e global" (United Nations, 2019e).

Em 2012, novamente no Rio de Janeiro, ocorreu a Conferência das Naçôes Unidas sobre Desenvolvimento Sustentável, a Rio+20, na qual destacamos o uso da expressão "Mãe-Terra", de especial interesse ao presente 
estudo. Também merece destaque a Cúpula de Desenvolvimento Sustentável (New York, 2015), pela adoção da Agenda 2030 e dos novos objetivos do Desenvolvimento Sustentável-ODS: 1) erradicação da pobreza, 2) fome zero e agricultura sustentável, 3) saúde e bem-estar, 4) educação de qualidade, 5) igualdade de Gênero, 6) água potável e saneamento, 7) energia limpa e acessível, 8) trabalho decente e crescimento econômico, 9) indústria, inovação e infraestrutura, 10) redução das desigualdades, 11) cidades e comunidades sustentáveis, 12) consumo e produção responsáveis, 13) ação contra a mudança global do clima, 14) vida na água, 15) vida terrestre, 16) paz, justiça e instituições eficazes, e 17) parcerias e meios de implementação (Naçóes Unidas Brasil, 2019b).

No campo doutrinário, diversas teorias surgiram sobre o direito ao desenvolvimento, cada uma delas construída a partir de diferentes premissas, recebendo grande destaque as ideias do ganhador do Prêmio Nobel de Economia Amartya Sen (2000), o qual critica a economia descritiva, desligada da ética, por esta identificar as ideias de crescimento do Produto Nacional Bruto (PNB) e desenvolvimento, e afirma que precisam ser considerados como indicativos do desenvolvimento também outros fatores, como educação, saúde e os direitos civis, influenciando, dessa forma, a criação do Índice de Desenvolvimento Humano (IDH), que considera a renda, saúde e educação.

Na obra "Desenvolvimento como liberdade", o referido autor afirma:

O desenvolvimento requer que se removam as principais fontes de privação de liberdade: pobreza e tirania, carência de oportunidades econômicas e destituição social sistemática, negligência dos serviços públicos e intolerância ou interferência excessiva de Estados repressivos. A despeito de aumentos sem precedentes na opulência global, o mundo atual nega liberdades elementares a um grande número de pessoas - talvez até mesmo à maioria. (Sen, 2000, p. 18)

Numa outra vertente, ganha destaque na doutrina o ideal de desenvolvimento sustentável, tendo como paradigma os esforços empreendidos no âmbito das Nações Unidas, inicialmente na Comissão Bruntland, de 1987, que o definiu como aquele que deve atender às necessidades do presente sem comprometer a possibilidade de atendê-las no futuro, através da superação da pobreza e do respeito aos limites ecológicos, aliados a um aumento do cres- 
cimento econômico, como condição de possibilidade para se alcançar uma maior sustentabilidade das condiçôes de vida globais (Delgado, 2001; Payão \& Santiago, 2018).

Sobre o tema da sustentabilidade, Juarez Freitas assevera:

trata-se do princípio constitucional que determina, com eficácia direta e imediata, a responsabilidade do Estado e da sociedade pela concretização solidária do desenvolvimento matéria e imaterial, socialmente inclusivo, durável e equânime, ambientalmente limpo, inovador, ético e eficiente, no intuito de assegurar, preferencialmente de modo preventivo e precavido, no presente e no futuro, o direito ao bem-estar. (2012, p. 41)

$\mathrm{Na}$ linha da mencionada Declaraçáo de Joanesburgo, John Elkington (2001), autor da teoria Triple Bottom Line, afirma que a sustentabilidade deve abarcar não apenas o prisma ambiental, mas também as perspectivas econômica e social, todos intimamente interligados, implicando uma redefinição radical das novas visōes de igualdade social, justiça ambiental e ética empresarial.

As ações da ONU e o ideal do desenvolvimento sustentável apresentaram resultados positivos no cenário internacional. Globalmente, o número de pessoas vivendo em extrema pobreza diminuiu mais da metade, visto que em 1990 eram 1,9 bilhão; a proporção de pessoas subnutridas em regiôes em desenvolvimento caiu quase pela metade desde 1990, de 23,3\% em 19901992 para 12,9\% em 2014-2016; a cada dia, morrem 17 mil crianças a menos do que em 1990; a mortalidade materna caiu quase $50 \%$, desde 1990; a matrícula na educação primária em países em desenvolvimento chegou a $91 \%$; em 2015, $91 \%$ da população global já usava uma fonte de água potável aprimorada, comparado a 76\% em 1990 etc. (Naçōes Unidas Brasil, 2019b).

Por outro lado, as questóes ambientais seguem gerando grande preocupação. A população global deve chegar a 9,6 bilhóes de pessoas até 2050 . Seria necessário o equivalente a três planetas para prover os recursos naturais necessários para sustentar os estilos de vida atuais. Mais de 1 bilhão de pessoas ainda não têm acesso à água potável. As emissões de gases de efeito estufa oriundos da atividade humana estão levando a mudanças climáticas, que alcançaram atualmente seu maior nível da história, aumentando quase 50\% desde 1990. A energia é o principal contribuinte para as mudanças climáticas, sendo 
responsável por cerca de $60 \%$ das emissóes globais totais de gases do efeito estufa. As fontes renováveis de energia, como vento, água, sol, biomas e energia geotermal são inexauríveis e limpas, mas, atualmente, constituem apenas $15 \%$ do conjunto global de energia (Naçôes Unidas Brasil, 2019b).

Treze milhôes de hectares de florestas estão sendo perdidos a cada o ano. Cerca de 1,6 bilhão de pessoas dependem das florestas para sua subsistência. Isso inclui 70 milhôes de indígenas. Florestas são o lar de mais de $80 \%$ de todas as espécies de animais, plantas e insetos terrestres. 2,6 bilhóes de pessoas dependem diretamente da agricultura, mas $52 \%$ da terra usada para agricultura é afetada moderada ou severamente pela degradação do solo. Das 8.300 raças animais conhecidas, $8 \%$ estão extintas e $22 \%$ estão sob risco de extinção. $80 \%$ das pessoas vivendo em área rural em países em desenvolvimento dependem da medicina tradicional das plantas para ter cuidados com a saúde básica (Nações Unidas Brasil, 2019b).

No Brasil, especificamente, o plano ambiental foi marcado por episódios gravíssimos, como, por exemplo, o vazamento de óleo na Baía de Guanabara, no Rio de Janeiro (2000), o vazamento de óleo nos Rios Barigui e Iguaçu, no Paraná (2000), o vazamento de barragem em Cataguases (2003), o rompimento de barragem em Mirai (2007), o vazamento de óleo na Bacia de Campos (2011), o incêndio na Ultracargo, no Porto de Santos (2015), o rompimento da barragem de Mariana, em Minas Gerais (2015), o rompimento da barragem de Brumadinho, em Minas Gerais (2019), o desmatamento e degradação ambiental na Amazônia (2019) e o óleo que atingiu recentemente a costa brasileira (2019) (Prado, 2019; Gragnani, 2019; Madeiro, 2019).

Os desastres e crises ambientais que afetaram o mundo nas últimas décadas e a forma como o discurso do desenvolvimento sustentável (entre outras teorias de desenvolvimento alternativo, que adjetivam a ideia de desenvolvimento) tem se mostrado lucrativo para determinados setores da economia, pela perspectiva antropocêntrica, eurocêntrica e economicista, têm levado alguns estudiosos a duvidarem da eficiência de tal teoria para a proteção do meio ambiente (Amaro, 2017).

De acordo com Ignacy Sachs (2009), um dos mais importantes teóricos sobre a matéria, 
O desenvolvimento sustentável é um desafio planetário. Ele requer estratégias complementares entre o Norte e o sul. Evidentemente, os padróes de consumo do Norte abastado são insustentáveis. O enverdecimento do Norte implica uma mudança no estilo de vida, lado a lado com a revitalizaçáo dos sistemas tecnológicos. No Sul, a reproduçáo dos padrôes de consumo do Norte em benefício de uma pequena minoria resultou em uma apartação social. $\mathrm{Na}$ perspectiva de democratização do desenvolvimento, o paradigma necessita ser complemente mudado. (p. 58)

A ideia de que o desenvolvimento econômico, como generalização, para todo o planeta, das formas de vida dos atuais povos ricos, é simplesmente irrealizável já consta na obra de Celso Furtado, para quem parece irrefutável que as economias da periferia nunca serão desenvolvidas, embora essa crença tenha sido de grande utilidade na mobilização dos povos da "periferia" do planeta a aceitarem enormes sacrifícios, legitimando a destruição de formas de cultura arcaicas e do próprio meio físico, para justificar formas de dependência que reforçam o caráter predatório do sistema produtivo (Furtado, 1974; Santiago \& Andrade, 2018).

As criticas às teorias de desenvolvimento alternativo, que adjetivam a ideia de desenvolvimento, a exemplo da ideia de desenvolvimento sustentável, correspondem às chamadas doutrinas de pós-desenvolvimento. Nesse sentido é a lição de Rogério Roque Amaro 2017

Foi a partir de 1992 que a corrente do "pós-desenvolvimento" se afirmou, propondo o "fim da era do desenvolvimento" e o início de uma nova era, liberta das influências negativas de um conceito, dominado por "intençôes geo-estratégicas de natureza capitalista, colonialista e patriarcal”

A partir de então, vários autores têm juntado as suas vozes a uma crítica contundente ao conceito de desenvolvimento. Entre eles, podem referir-se os nomes de Alberto Acosta, Arturo Escobar, Boaventura de Sousa Santos, Claude Alvares, Eduardo Gudynas, Gilbert Rist, Gustavo Esteva, Ivan Illich, Majid Rahnema, Serge Latouche e Wolfgang Sachs, entre muitos outros.

Teórico do decrescimento, o francês Serge Lautouche (2009) é um crítico do conceito de desenvolvimento sustentável. Segundo o autor, afirmar que o crescimento infinito é incompatível com um mundo finito é evidência facil- 
mente compartilhável e pouco significa se não se questiona de fato a lógica do crescimento sistemático e irrestrito (Santiago \& Andrade, 2018).

Nas palavras do Latouche,

o desenvolvimento é uma palavra tóxica, qualquer que seja o adjetivo com que o vistam. Para realizar a quadratura do círculo, o desenvolvimento sustentável agora encontrou seu instrumento privilegiado: os "mecanismos limpos de desenvolvimento", expressão que designa tecnologias poupadoras de energias ou de carbono, sob o manto da ecoeficiência. Continuamos na diplomacia verbal. As inegáveis e desejáveis performances da técnica não questionam a lógica suicida do desenvolvimento. (2009, pp. 8-9)

A bandeira do decrescimento reúne, assim, aqueles que procedem a uma crítica radical do desenvolvimento baseado no consumo e querem desenhar um projeto alternativo, uma política de pós-desenvolvimento, tendo como meta uma sociedade que viva melhor, trabalhando e consumindo menos, abrindo espaço para a inventividade a criatividade. Tal projeto envolveria a articulação sistemática de oito mudanças interdependentes: reavaliar, reconceituar, reestruturar, redistribuir, relocalizar, reduzir, reutilizar e reciclar (Latouche, 2009; Santiago \& Andrade, 2018).

Numa perspectiva de complexidade, sem descartar por completo a teoria do desenvolvimento sustentável, Edgar Morin faz a seguinte ressalva:

a idéia de "suportabilidade" (ou sustentabildiade) acrescenta ao desenvolvimento um conjunto de açóes voltado à salvaguarda da biosfera e, correlativamente, à salvaguarda das geraçôes futuras. Essa noção contém um componente ético importante, mas não poderia aperfeiçoar em profundidade a própria ideia de desenvolvimento. Ela não faz senão suavizá-la, recobri-la com uma pomada calmante. (2013, p. 32)

$\mathrm{O}$ atual estado de coisas permite concluir que o fortalecimento de uma consciência e valores ecológicos impóe o reconhecimento de mais protagonismo para a Natureza e, consequentemente, a quebra do padrão antropocentrista nascido da Revolução Industrial e da Revolução Francesa, em reação aos teocentrismos dominantes. Como características desse antropocentrismo estão a hiper valorização da liberdade, da razão, e o domínio utilitarista da Natureza (Amaro, 2017). 
Nas palavras de Rogério Roque Amaro,

[...] ambos os modelos de referência, que se confrontaram na Modernidade, sobretudo na segunda metade do século XX - capitalismo e socialismo -, assumiram profunda e intrinsecamente uma natureza e um modo de exploração antropocêntrico, com graves destruiçóes da Natureza e da Vida, em geral, no primeiro caso com foco no indivíduo (e na sua Liberdade), no segundo com foco no colectivo (e no enunciado da Igualdade): está-se assim em presença de dois antropocentrismos, um ideologicamente mais individualista, outro mais coletivista. (2017, pp. 75-111)

A quebra da visão antropocentrista implica em valorizar as sociedades tradicionais do Sul, seus conhecimentos ancestrais, mormente suas relaçóes comunitárias e o respeito à Natureza, na busca de uma cosmovisão, na qual homem e Natureza dividem o protagonismo, como partes integrantes do mesmo planeta. É sobre essa cosmovisão e suas implicaçóes na seara jurídica que se tratará a seguir.

\section{A necessidade da quebra do paradigma antropocêntrico para a proteçáo dos direitos da natureza}

A Era Moderna, ao instrumentalizar o sentido das coisas, colocando o homem no centro axiológico do universo moral, promoveu o renascimento do antropocentrismo, acompanhado da laicização das mentalidades, desvalorizando perspectivas diversas. (Gordilho, 2008).

Sobre os abalos sofridos pela perspectiva antropocêntrica ao longo do tempo, enumera Heron José de Santana Gordilho:

Primeiro, quando Copérnico demonstrou que a terra não era o centro do universo, mas apenas um pequeno fragmento de um vasto sistema cósmico. Segundo, quando Charles Darwin provou que a espécie humana não surgiu pronta, como diz a Biblia, e que ela possui um ancestral comum com os grandes primatas. E, por fim, quando o Freud demonstrou a irracionalidade humana e que o ego não é senhor dentro de sua própria casa, uma vez que a maior parte das nossas açôes são inconscientes. (2008, p. 33) 
Das vivências tradicionais das comunidades indígenas dos Andes, afirmou-se uma ideia de "Boa Vida", de "Buen Vivir", em harmonia com a natureza e outros que nos rodeiam, como tradução, em língua castelhana, de quatro expressôes de povos locais: "Sumak Kawsay" (povo Quíchua, descendentes dos Incas, distribuídos por Equador, Bolívia, Peru, Argentina, Chile e Colômbia), no sentido de comunhão com a Mãe-Terra, a "Pachamama" ou "Pacha Mama"; "Suma Qamaña” (povo Aymará, presente na Bolívia, Argentina, Chile e Peru), também tem o sentido de "vida plena", "boa vida", "conviver"; "Teko Porä" (povo Guarani, na Bolívia, Argentina, Brasil, Paraguai e Uruguai), com o significado de "bem viver"; e "Teko Kavi" (também do povo Guarani), com o sentido de "boa vida" ou o "bom modo de ser e viver" (Amaro, 2017).

Não se deve olvidar, ainda, outros conceitos, também com origem em "Epistemologias do Sul", como: "Felicidade" ou "Felicidade Interna Bruta" (Butão), assentada na conjugação de nove dimensôes, de inspiração budista, quais sejam, bem-estar psicológico, saúde, uso equilibrado do tempo, vitalidade comunitária, educaçáo, diversidade e resiliência cultural, diversidade e resiliência ecológica, boa governança e padrão de vida; "Wellbeing" / "Bem-estar" (comunidades indianas e oriundas da África do Sul), partindo das dimensôes subjectiva ou psicológica, material ou objetiva e relacional; "Florescimento humano" (“human flourishing”), oriundo da Saúde Mental e da sua abordagem, a partir da Psicologia Positiva (ou Apreciativa), envolvendo o bem-estar emocional, bem-estar psicológico e bem-estar social ; e "Ubuntu" (povo xhosa, da África do Sul), assinalando a importância da interconexão dos seres humanos entre si, estando o bem-estar de um ligado ao bem-estar do outro; e noflay (língua autóctone wolof, do Senegal), que designa o equivalente senegalês ao conceito andino de "buen vivir", ressaltando as perspectivas cultural, filosófica e moral da pessoa. Tais propostas enriquecem a reflexão por agregar não apenas a visão andina, mas uma visão plural do "Sul" (Amaro, 2017).

Em consonância com esse paradigma, em 2009, a Assembléia Geral das Nações Unidas, em sua 63 $3^{\text {a }}$ Sessão, proclamou 22 de abril como o Dia Internacional da Mãe Terra (A/RES/63/278), com o reconhecimento, pelos Estados Membros, de que a Terra e seus ecossistemas são nosso lar comum, sendo 
necessário promover a Harmonia com a Natureza, a fim de alcançar um equilíbrio justo entre as necessidades econômicas, sociais e ambientais do presente e do futuro. No mesmo ano, a Assembléia Geral adotou sua primeira resolução sobre Harmonia com a Natureza (A/RES/64/196) (United Nations, 2019d).

A partir dessas discussóes, em 2010 surgem as diretrizes para a criação do Projeto Harmony with Nature, incluindo a construção do Website e promoção dos Diálogos Interativos anuais sobre o tema, a partir de 2011. O primeiro Diálogo Iterativo, em 2011, discutiu maneiras de promover uma abordagem holística do desenvolvimento sustentável em Harmonia com a Natureza, além de compartilhar experiências nacionais sobre critérios e indicadores para medir o desenvolvimento sustentável em harmonia com a natureza (United Nations, 2019d).

O documento final da Conferência das Naçôes Unidas sobre Desenvolvimento Sustentável (Rio + 20), em 2012, “O futuro que queremos”, dedicou o parágrafo 39 sobre Harmonia com a Natureza, com a seguinte redação (United Nations, 2019c):

Reconhecemos que o planeta Terra e seus ecossistemas são a nossa casa e que a Mãe Terra é uma expressão comum em vários países e regiōes e notamos que alguns países reconhecem os direitos da natureza no contexto da promoçáo do desenvolvimento sustentável. Estamos convencidos de que, a fim de alcançar um justo equilíbrio entre as necessidades econômicas, sociais e meio ambiente das geraçóes presentes e futuras, é necessário promover a harmonia com a natureza.

Em 2016, o projeto se abre para a participação de experts, que atuam com a perspectiva biocêntrica, para o reconhecimento dos direitos da Mãe-Terra, a fim de inspirar cidadáos e sociedades a reconsiderar como eles interagem com o mundo natural para implementar os Objetivos de Desenvolvimento Sustentável em Harmonia com a Natureza, observando que alguns países reconhecem os direitos da natureza no contexto da promoção do desenvolvimento sustentável (United Nations, 2019d).

Desde entáo, Assembléia Geral adota as resoluçóes sobre Harmonia com a Natureza, num esforço de definir um relacionamento não antropocêntrico com a Natureza. A construção de um novo paradigma não-antro- 
pocêntrico, parte da premissa de que a base fundamental para as açóes em relação ao meio ambiente se baseia não apenas nas preocupações humanas (United Nations, 2019d).

No âmbito internacional, os países latino-americanos têm sido pioneiros no reconhecimento dos direitos da natureza, por diversas vias. Merece destaque o Equador, que em sua Constituição, de 2008, no art. 71, dispóe: "a natureza ou Pacha Mama, onde se reproduz e se realiza a vida, tem direito que se respeite integralmente a sua existência e a manutenção e regeneração de seus ciclos vitais, estruturas, funçōes e processos evolutivos".

A Constituição da Bolívia, de 2009, em seu preâmbulo, faz referencia às expressões "Madre Tierra" e "Pachamama”, demonstrando uma visível quebra de antopocentrismo, ao estabelecer, em seu art. 33: "Las personas tienen derecho a un medio ambiente saludable, protegido y equilibrado. El ejercicio de este derecho debe permitir a los individuos y colectividades de las presentes y futuras generaciones, además de otros seres vivos, desarrollarse de manera normal y permanente" (Bolívia, 2019).

Além disso, a Lei Federal 071/2010, da Bolívia, também conhecida como Lei dos direitos da Mãe-Terra, enuncia, em seu art. 1: "La presente Ley tiene por objeto reconocer los derechos de la Madre Tierra, así como las obligaciones y deberes del Estado Plurinacional y de la sociedad para garantizar el respeto de estos derechos" (Bolívia, 2019).

A Colômbia tratou o tema através de suas regulamentaçóes locais. Em 2016, a Corte Constitucional da Colômbia reconheceu o Rio Atrato como sujeito de direito. Em 2017, a Corte Suprema de Justiça da Colômbia estabeleceu que os animais são sujeitos de direitos. Em 2018, A Corte Suprema de Justiça outorgou direitos à região amazônica colombiana. No mesmo ano, o Tribunal Administrativo de Boyacá declarou o Páramo de Pisba como sujeito de direitos, e o Primeiro Tribunal Penal do Circuito de Cartagena ordenou ao Estado da Colômbia proteger e preservar a vida das abelhas como agentes plonizadores. Em 2019, o Tribunal Civil Municipal Colombiano de La Plata - Huila reconheceu o Rio La Plata como sujeito de direitos; o Tribunal Administrativo de Tolima reconheceu os rios Coello, Combeima y Cocora com a mesma condição; e igualmente ocorreu com o Rio Cauca, por determi- 
nação do Tribunal Superior de Medelín. Também em 2019, o departamento de Nariño se converteu no primeiro do país a reconhecer a Natureza como sujeitos de direitos, pelo Decreto 348 (United Nations, 2019d).

No México, em 10 de junho de 2019, o Congresso do Estado de Colima aprovou uma emenda à Constituição Estadual que reconhece os Direitos da Natureza. Em 31 de janeiro de 2017, a nova Constituiçáo da Cidade do México adotou os direitos da Natureza, em seu artigo 18. A Constituição do Estado de Guerrero, alterada em 30 de junho de 2014, reconheceu, em seu art. $2^{\circ}$, os Direitos da Natureza (United Nations, 2019d).

O Parlamento de Uganda reconheceu os direitos fundamentais da Natureza de ser, evoluir e regenerar na Lei Nacional do Meio Ambiente de 2019. Na Nova Zelândia, em março de 2017, o Rio Whanganui recebeu o status legal de pessoa, e, em julho de 2014, Te Urewera, anteriormente um parque nacional, foi removido do sistema nacional de parques e foi legalmente reconhecido como "entidade legal" com "todos os direitos, poderes, deveres e responsabilidades de uma pessoa coletiva", gerenciado pelo novo Conselho de Te Urewera, responsável por agir em defesa e em nome de Te Urewera. A Austrália reconheceu por lei, em 1 de dezembro de 2017, o Rio Yarra como uma entidade viva indivisível que merece proteção. A lei também reconhece a conexão intrínseca dos proprietários tradicionais ao rio Yarra e os reconhece como os guardióes da terra e da hidrovia que eles chamam de Birrarung (United Nations, 2019d).

$\mathrm{Na}$ França, uma reforma constitucional para alterar a Constituição (1958) e a Carta do Meio Ambiente (2004) foi iniciada em 10 de julho de 2018, contendo mais de vinte alteraçóes abordando, entre outros, os direitos de vida, bem-estar animal, bens comuns globais, o crime de ecocídio e o princípio da não regressão ambiental foram apresentadas pelos parlamentares, sinalizando uma tendência para um processo constitucional mais centrado na Terra (United Nations, 2019d).

Especificamente ao meio ambiente, a Constituição Federal dedicou o art. 225, pelo qual, em seu caput, "todos têm direito ao meio ambiente ecologicamente equilibrado, bem de uso comum do povo e essencial à sadia qualidade de vida, impondo-se ao Poder Público e à coletividade o dever de defendê-lo e preservá-lo para as presentes e futuras geraçóes” (Brasil, 1988). 
Pela análise do mencionado art. 225, da Constituição Federal brasileira, resta claro que para o ordenamento brasileiro, o meio ambiente, é um direito sobre outro direito, ou seja, o direito a um meio ambiente equilibrado, a uma sadia qualidade de vida, de interesse difuso, pertencendo a cada um e a todos ao mesmo tempo, sem identificação do seu titular ou passível de divisão. A perspectiva é, assim, antropocêntrica, calcada na dignidade humana, sem divisão do protagonismo (Gordilho, 2008).

$\mathrm{Na}$ perspectiva dos direitos da natureza, a legislaçáo brasileira projetada merece destaque. No município de Sáo Paulo, há o Projeto de Emenda à Leio Orgânica do Município 04-00005/2015, que propóe incluir na referida lei orgânica um dispositivo (180 A) "considerando que os membros da natureza possuem direitos intrínsecos à vida e à manutençáo de seus processos ecossistêmicos, em interdependência com a vida digna dos cidadáos, com o objetivo de alcançar a sustentabilidade na cidade" (United Nations, 2019d).

Por sua vez, em 2017, o Município de Bonito, no Estado de Pernambuco, alterou a sua lei orgânica para reconhecer os direitos da Natureza, movimento seguido, em 2018, pelo Município de Paudalho, também no Estado de Pernambuco, também através de emenda à Lei Orgânica Municipal. Em março de 2018, foi apresentado projeto de lei que concede o reconhecimento dos direitos da Natureza, na Câmara Municipal de Fortaleza (United Nations, 2019d).

Um passo importante para o reconhecimento dos direitos da natureza no direito brasileiro ocorreu com o julgamento do Recurso Especial n ${ }^{\circ}$ 1.797.175 - SP, pelo Superior Tribunal de Justiça, que teve como relator o Ministro Og Fernandes. O objeto de análise foi o caso de guarda de animal silvestre apreendido pelo Instituto Brasileiro do Meio Ambiente e dos Recursos Naturais Renováveis - Ibama, órgão responsável pela proteção da fauna brasileira.

O referido julgado aborda, em sua fundamentação, a perspectiva ecológica do princípio da dignidade da pessoa humana, defendendo a quebra do paradigma antropocêntrico kantiano, o que seria uma emergência, diante da crise ecológica (Sarlet \& Fensterseifer, 2017).

O debate acerca dos direitos da Natureza, impulsionado pela Assembléia Geral das Naçóes Unidas, culminou com a elaboração de uma proposta de 
Declaração Universal dos Direitos da Mãe Natureza - aprovado pelo povo participante da World People's Conference on Climate Change and the Rignts of Mother Earth, em abril de 2010, na Bolívia, documento este posteriormente levado à Rio+20. Não se observou, ainda, entretanto, o reconhecimento destes direitos de forma universal (Oliveira, 2016).

A necessidade de uma mudança de visão mais firme em torno na ecologia é bem retratada por Félix Guattari, ao afirmar que

Os movimentos ecológicos atuais têm certamente muitos méritos, mas penso que, na verdade, a questão ecosófica global é importante demais para ser deixada a algumas de suas correntes arcaizantes e folclorizantes, que às vezes optam deliberadamente por recusar todo e qualquer engajamento político em grande escala. A conotação da ecologia deveria deixar de ser vinculada à imagem de uma pequena minoria de amantes da natureza ou de especialistas diplomados. Ela póe em causa o conjunto da subjetividade e das formaçóes de poder capitalísticos - os quais não estão de modo algum seguros de que continuarão a vencê-la, como foi o caso na última década. (2012, p. 36)

De fato, uma verdadeira resposta à crise ecológica deve se observar em escala planetária e envolve uma revoluçáo política, social e cultural, reorientando a própria lógica da produção de bens materiais e imateriais, além dos domínio da sensibilidade, da inteligência e do desejo (Guattari, 2012).

\section{Conclusóes}

As açôes da ONU e o ideal do desenvolvimento sustentável apresentaram resultados positivos no cenário internacional, mas por outro lado, as questóes ambientais seguem gerando grande preocupaçáo, especialmente diante dos recentes desastres ambientais que assolaram o Brasil nos últimos anos.

Os desastres e crises ambientais acabam por aclarar a forma como o discurso do desenvolvimento sustentável tem se mostrado ineficiente para alcançar os objetivos da proteçấo do meio ambiente, e, ao mesmo tempo, possibilitado o aumento do lucro de determinados setores da economia global, conforme apontado pelas doutrinas de pós-desenvolvimento.

A partir dessa constatação, pode-se afirmar que uma efetiva proteção do meio ambiente implica conferir maior protagonismo à Natureza, atribuindo- 
-lhe direitos, numa quebra da visão antropocentrista. Isso implica em valorizar as sociedades tradicionais do Sul, seus conhecimentos ancestrais, mormente suas relações comunitárias e o respeito à Natureza, na busca de uma cosmovisão na qual homem e Natureza dividem o protagonismo, como partes integrantes do mesmo planeta.

A criação do Projeto Harmony with Nature, de iniciativa das Naçóes Unidas, tem impulsionado esse movimento. A Assembléia Geral tem adotado as resoluçóes sobre Harmonia com a Natureza, num esforço de definir um relacionamento não antropocêntrico com a Natureza, num novo paradigma fundado não apenas nas preocupaçôes humanas.

No âmbito internacional, os países latino-americanos têm sido pioneiros no reconhecimento dos direitos da natureza, por diversas vias, merecendo destaque os casos de Ecuador e Bolívia, pelas suas respectivas constituiçôes, embora o avanço já se note em diversos países. Há também um esforço internacional para a elaboração de uma Declaração Universal dos Direitos da Mãe Terra, que certamente levaria a questão a um patamar de maior destaque.

No Brasil, há projetos, leis municipais e decisão do Superior Tribunal de Justiça, no intuito de se conferir direitos à Natureza. Todavia, no seu art. 225, a Constituiçáa Federal brasileira trata expressamente o meio ambiente como bem de uso comum do povo, ou seja, na perspectiva antropocêntrica, calcada na dignidade humana, sem divisão do protagonismo.

\section{Referências}

Amaro, R. R. (2017). Desenvolvimento ou Pós-Desenvolvimento? Des-Envolvimento e... Noflay! Cadernos de Estudos Africanos, 34, 75-111. https://doi.org/10.4000/cea.2335

Bolívia. (2019). Constitución Politica del Estado. https://www.oas.org/dil/esp/Constitucion_ Bolivia.pdf

Brasil. (2019). Constituição Federal. Promulgada em 5 de outubro de 1988. http://www.planalto. gov.br/ccivil_03/constituicao/constituição.htm

Delgado, A. P. T. (2001). O direito ao desenvolvimento na perspectiva da globalização: paradoxos e desafios. Renovar.

Elkington, J. (2001). Canibais com garfo e faca. Makron Books.

Freitas, J. (2012). Sustentabilidade: direito ao futuro (2 ed.). Fórum.

Furtado, C. (1974). O Mito do Desenvolvimento econômico (4 ed.). Paz e Terra. 
Gordilho, H. J. S. (2008). Abolicionismo animal. Evolução.

Gragnani, J. (2019). Essenciais para o planeta, manguezais no Nordeste são 'sufocados' por petróleo. BBC News Brasil. https://www.bbc.com/portuguese/brasil-50132770

Guattari, F. (2012). As três ecologias (21 ed.). Papirus.

Latouche, S. (2009). Pequeno tratado do decrescimento sereno. Martim Fontes.

Madeiro, C. (2019). Desmatada e aquecida, Amazônia perde até 50 \% da capacidade de reciclar água. UOL. https://noticias.uol.com.br/meio-ambiente/ultimas-noticias/redacao/2019/09/05/ desmatada-e-aquecida-amazonia-perde-ate-50-da-capacidade-de-reciclar-agua.htm

Morin, E. (2013). A via para o futuro da humanidade. Bertrand Brasil.

Naçóes Unidas Brasil. (2019a). A ONU e o meio ambiente. https://nacoesunidas.org/acao/meio-ambiente/

Naçôes Unidas Brasil. (2019b). Conheça os novos 17 Objetivos de Desenvolvimento Sustentável da ONU. https://nacoesunidas.org/conheca-os-novos-17-objetivos-de-desenvolvimento-sustentavel-da-onu/

Oliveira, V. H. (2016). Direitos da Natureza. Lumen Juris.

Payão, J. V., \& Santiago, M. R. (2018). A função social e solidária da empresa no âmbito das relaçôes de trabalho. Revista Direito da Cidade, 8(3), 1120-1136. https://doi. org/10.12957/rdc.2016.22109

Prado, D. (2019). Principais desastres ambientais no Brasil e no mundo. Jornal da Unicamp. https://www.unicamp.br/unicamp/ju/noticias/2017/12/01/principais-desastres-ambientais-no-brasil-e-no-mundo

Sachs, I. (2009). Caminhos para o desenvolvimento sustentável. Garamond.

Santiago, M. R., \& Andrade, S. L. (2018). A construçáo complexa do desenvolvimento: uma análise pelo prisma da teoria da complexidade. Revista Brasileira de Direito, 14(2), 180-197.

Sarlet, I. W., \& Fensterseifer, T. (2017). Direito constitucional ambiental: Constituição, direitos fundamentais e proteçâo do ambiente (5. ed.).

Sen, A. (2000). Desenvolvimento como liberdade. Companhia das Letras, 2000.

Silveira, V. O., \& Naspolini, S. H. F. (2013). Direito ao desenvolvimento no Brasil do Século XXI: uma análise da normatizaçáo internacional e da Constituição brasileira. In A. Monteiro \& D. Abreu (Coords.), Direito e desenvolvimento no Brasil no Século XXI. Ipea: Conpedi.

United Nations. (2019a). Agenda 21. https://sustainabledevelopment.un.org/content/documents/ Agenda21.pdf

United Nations. (2019b). Declaration on the Right to Development. http://legal.un.org/avl/ha/ $\mathrm{drd} / \mathrm{drd} . \mathrm{html}$

United Nations. (2019c). Future we want - Outcome document. https://sustainabledevelopment. un.org/futurewewant.html

United Nations. (2019d). Harmony with Nature. http://www.harmonywithnatureun.org/ 
United Nations. (2019e). Johannesburg Declaration on Sustainable Development. https://www. un.org/esa/sustdev/documents/WSSD_POI_PD/English/POI_PD.htm

United Nations. (2019f). Report of the World Commission on Environment and Development: Our Common Future. https://sustainabledevelopment.un.org/content/documents/5987our-common-future.pdf

United Nations. (2019g). Vienna declaration and programme of action. https://www.ohchr.org/ EN/ProfessionalInterest/Pages/Vienna.aspx 